Pa-thai Yenchitsomanus · Nunghathai Sawasdee

Atchara Paemanee · Thitima Keskanokwong

Somkiat Vasuvattakul · Sasitorn Bejrachandra

Warunee Kunachiwa - Supan Fucharoen

Prapaporn Jittphakdee · Wanwimon Yindee

Charupon Promwong

\title{
Anion exchanger 1 mutations associated with distal renal tubular acidosis in the Thai population
}

Received: 5 June 2003 / Accepted: 3 July 2003 / Published online: 21 August 2003

(C) The Japan Society of Human Genetics and Springer-Verlag 2003

\begin{abstract}
We have previously demonstrated that compound heterozygous (SAO/G701D) and homozygous (G701D/G701D) mutations of the anion exchanger 1 $(A E 1)$ gene, encoding erythroid and kidney AE1 proteins, cause autosomal recessive distal renal tubular
\end{abstract}

P. Yenchitsomanus $(\bowtie) \cdot$ N. Sawasdee

A. Paemanee $\cdot$ T. Keskanokwong

Division of Medical Molecular Biology,

Department of Research and Development,

Faculty of Medicine Siriraj Hospital, Mahidol University,

Bangkok 10700, Thailand

E-mail: grpye@mahidol.ac.th

Tel.: + 66-2-4184793

Fax: + 66-2-4184793

P. Yenchitsomanus · A. Paemanee

Medical Biotechnology Unit,

National Center for Biotechnology and Genetic Engineering (BIOTEC),

National Science and Technology Development Agency (NSTDA), Bangkok, Thailand

\section{S. Vasuvattakul}

Division of Nephrology, Department of Medicine,

Faculty of Medicine Siriraj Hospital,

Mahidol University, Bangkok, Thailand

\section{S. Bejrachandra}

Department of Transfusion Medicine,

Faculty of Medicine Siriraj Hospital,

Mahidol University, Bangkok, Thailand

\section{W. Kunachiwa}

Department of Clinical Immunology,

Faculty of Associated Medical Sciences,

Chiang Mai University, Chiang Mai, Thailand

\section{Sp. Fucharoen}

Department of Clinical Chemistry,

Faculty of Associated Medical Sciences,

Khon Kaen University, Khon Kaen, Thailand

P. Jittphakdee $\cdot$ W. Yindee $\cdot$ C. Promwong

Department of Pathology, Faculty of Medicine,

Prince of Songkla University, Songkla, Thailand acidosis (AR dRTA) in Thai patients. It is thus of interest to examine the prevalence of these mutations in the Thai population. The SAO and G701D mutations were examined in 844 individuals from north, northeast, central, and south Thailand. Other reported mutations including $\mathrm{R} 602 \mathrm{H}, \Delta \mathrm{V} 850$, and $\mathrm{A} 858 \mathrm{D}$ were also examined in some groups of subjects. The SAO mutation was common in the southern Thai population; its heterozygote frequency was $7 / 206$ and estimated allele frequency $1.70 \%$. However, this mutation was not observed in populations of three other regions of Thailand. In contrast, the G701D mutation was not found in the southern population but was observed in the northern, northeastern, and central populations, with heterozygote frequencies of $1 / 216,3 / 205$, and $1 / 217$, and estimated allele frequencies of $0.23 \%, 0.73 \%$, and $0.23 \%$, respectively. The higher allele frequency of the G701D mutation in the northeastern Thai population corresponds to our previous finding that all Thai patients with AR dRTA attributable to homozygous G701D mutation originate from this population. This suggests that the G701D allele that is observed in this region might arise in northeastern Thailand. The presence of patients with compound heterozygous $\mathrm{SAO} / \mathrm{G} 701 \mathrm{D}$ in southern Thailand and Malaysia and their apparently absence in northeastern Thailand indicate that the G701D allele may have migrated to the southern peninsular region where SAO is common, resulting in pathogenic allelic interaction.

Keywords Anion exchanger 1 (AE1) - Band 3 protein Southeast Asian ovalocytosis (SAO) · Distal renal tubular acidosis $\cdot$ Thai

\section{Introduction}

The human anion exchanger 1 (AE1 or SLC4A1; MIM 109270) gene, located on chromosome 17q21 (Lux 
et al. 1989), encodes AE1 or band 3 protein in erythrocytes and $\alpha$-intercalated cells of kidney (Sahr et al. 1994). Erythroid AE1 (eAE1) contains 911 amino acids, whereas kidney AE1 (kAE1) lacks 65 amino acids at its $\mathrm{N}$-terminus (Kollert-Jons et al. 1993) because of the use of different promoters (Sahr et al. 1994). The promoter for eAE1 is upstream of exon 1 and that for kAE1 is within intron 3 of the gene. AE1 is an integral membrane glycoprotein containing a long cytoplasmic $\mathrm{N}$-terminus ( $\sim 400$ amino acids), 12-13 transmembrane domains, and a short cytoplasmic C-terminus ( $\sim 35$ amino acids). In erythrocytes, eAE1 forms dimers, tetramers, or higher oligomers on the cell membrane; in addition to having an anion $\left(\mathrm{Cl}^{-} / \mathrm{HCO}^{-}{ }_{3}\right)$ exchange function, these eAE1 oligomers serve as anchor proteins of the cytoskeleton network, binding to ankyrin, bands 4.1 and 4.2, and cytoplasmic proteins (Tanner 1993, 1997). In the $\alpha$-intercalated cells, kAE1 is located at the basolateral membrane (Kollert-Jons et al. 1993) and functions in anion $\left(\mathrm{Cl}^{-} / \mathrm{HCO}_{3}^{-}\right)$exchange.

Because of the expression of AE1 in two different cells with distinct functions, AE1 mutations show pleiotrophic effects resulting in two distinct and seemingly unrelated phenotypes: hereditary spherocytosis (or other forms of erythrocyte abnormalities) and distal renal tubular acidosis (dRTA). AEl mutations have been found to account for approximately $20 \%$ of spherocytosis and almost all ovalocytosis in Southeast Asia (Tanner 1997; Tse and Lux 1999; Bruce and Tanner 1996). Southeast Asian ovalocytosis (SAO), a wellknown erythrocyte disorder that is widespread in the Southeast Asian regions, is caused by a deletion of $27 \mathrm{bp}$ in codons $400-408$ in exon 11 (Ex11 227 ) of $A E 1$ leading to an in-frame lack of 9 amino acids in the protein (Jarolim et al. 1991), which is inactive for anion transport. AEl mutations also result in dRTA, because the defect in AE1 affects anion $\left(\mathrm{Cl}^{-} / \mathrm{HCO}_{3}^{-}\right)$exchange at the basolateral membrane of the $\alpha$-intercalated cells in the distal nephron of the kidney (Rodriguez-Soriano 2000; Batlle et al. 2001; Alper 2002). The accumulation of bicarbonate $\left(\mathrm{HCO}_{3}{ }^{-}\right)$within these cells may lead to the reduction of carbonic acid $\left(\mathrm{H}_{2} \mathrm{CO}_{3}\right)$ dissociation and hydrogen $\left(\mathrm{H}^{+}\right)$ion secretion at the apical membrane of the cells and, finally, to acidosis.

During the past few years, abnormalities of $A E 1$ associated with dRTA have been extensively investigated, and its mutations have been found in several kindreds with autosomal dominant (AD) dRTA (Bruce et al. 1997; Jarolim et al. 1998; Karet et al. 1998; Sritippayawan et al. 2003). The characterization of $A E 1$ in AD dRTA has identified multiple families (Bruce et al. 1997; Jarolim et al. 1998; Karet et al. 1998; Sritippayawan et al. 2003) with missense mutations in codon 589 (R589H, R589S, R589C), one family (Bruce et al. 1997) with an S613F mutation, and another family (Karet et al. 1998) with an 11-amino-acid deletion at the carboxy terminus (R901X). Functional analysis of R589 mutations, however, has revealed only a modest reduction in $\mathrm{AE} 1-$ mediated ${ }^{36} \mathrm{Cl}^{-}$transport when expressed in
Xenopus oocytes, whereas the S613F mutation is associated with the upregulation of anion transport. The mechanism by which mutant AE1 causes AD dRTA may involve impaired trafficking of the protein to cell surface and a dominant negative effect attributable to the formation of heterodimers between mutant and normal proteins (Quilty et al. 2002a, 2002b).

A novel $A E 1$ missense mutation linked to autosomal recessive (AR) dRTA and xerocytic hemolytic anemia in which red cell anion transport is normal has been reported in a Thai family (Tanphaichitr et al. 1998). The two affected individuals, siblings of the same family, are homozygous for the functionally defective mutation, G701D (band 3 Bangkok I). The $A E 1$ G701D mutation results in inactive anion transport caused by impaired protein trafficking as shown by expression studies in Xenopus oocytes. Co-expression of $A E 1$ G701D with the erythroid AE1 chaperonin, glycophorin A (GPA), rescues both AE1-mediated $\mathrm{Cl}^{-}$transport and AE1 surface expression in oocytes.

Co-existence of SAO and dRTA is not normally found in the same individual. However, the two conditions can co-exist as the result of compound heterozygosity between SAO and other $A E 1$ mutations. Our group has recently described a novel compound heterozygosity of $A E 1$ mutations causing AR dRTA in patients with SAO (Vasuvattakul et al. 1999). Two clinically affected individuals from two unrelated families from southern Thailand had one $A E 1$ allele with an SAO mutation and the other allele with the missense G701D mutation (SAO/G701D). The patients with this compound heterozygosity presented with ovalocytic red cells and metabolic acidosis with failure to thrive and hypokalemia. However, they had no sign of hemolytic anemia. SAO/G701D and other genotypes including $\mathrm{SAO} / \Delta \mathrm{V} 850, \mathrm{SAO} / \mathrm{A} 858 \mathrm{D}, \Delta \mathrm{V} 850 / \Delta \mathrm{V} 850$, and $\Delta \mathrm{V} 850 /$ A858D have also been observed in Malaysian and Papua New Guinean patients with dRTA (Bruce et al. 2000).

We have recently identified an additional seven patients with AR dRTA from five families exhibiting the homozygous $A E 1$ G701D mutation in Thailand (Yenchitsomanus et al. 2002). None of the patients had xerocytic hemolytic anemia, which was found in two patients with the homozygous $A E 1$ G701D mutation previously documented (Tanphaichitr et al. 1998). This different finding may be attributable to the patients that we studied also not being homozygous for hemoglobin $\mathrm{E}$, as were both patients in the previous work (Tanphaichitr et al. 1998). A new patient with AR dRTA resulting from the same genotype has recently been identified in another family (unpublished). It is of great interest that all Thai patients with AR dRTA attributable to homozygous $A E 1$ G701D mutation originate from northeastern Thailand, and those that result from compound heterozygous $\mathrm{SAO} / \mathrm{G} 701 \mathrm{D}$ mutations inhabit southern Thailand (Vasuvattakul et al. 1999) and Malaysia (Bruce et al. 2000), a southern neighboring country of Thailand. This has led to the suggestion that 
the $A E 1$ G701D mutation might be of ancient origin (Yenchitsomanus et al. 2002), and that it might have evolved in this region of Southeast Asia, especially in Thailand. To investigate the prevalence of the SAO and G701D mutations, their migration, and their interaction, we have therefore analyzed these two mutations in the Thai population.

\section{Subjects and methods}

The subjects were healthy individuals who were school and university students and blood-donor volunteers anonymously recruited with informed consent. The persons who were not native of relevant regions were excluded. Altogether, 844 subjects from four geographic areas of Thailand (Fig. 1), including 216 individuals from Chiang Mai (North), 205 from Khon Kaen (Northeast), 217 from Bangkok (Central), and 206 from Songkla (South) were studied. Blood samples $(5-10 \mathrm{ml})$ were collected from these subjects. DNAs were prepared from leukocytes by the standard method of proteinase $\mathrm{K}$ digestion, phenol/chloroform extraction, and ethanol precipitation and used for analyses of AE1 mutations.

Previously, we had identified and reported several cases with compound heterozygous (SAO/G701D) and homozygous (G701D/ G701D) mutations of $A E 1$ (Vasuvattakul et al. 1999; Yenchitsomanus et al. 2002). The $A E 1$ mutations in the patients were initially screened by the polymerase chain reaction/single-stranded conformation polymorphism (PCR-SSCP) technique and characterized by nucleotide sequencing. We had also developed simple methods for detection of the SAO (Vasuvattakul et al. 1999) and G701D (Yenchitsomanus et al. 2002) mutations. These methods were therefore employed in the present study. In addition, the DNA samples with known SAO and G701D mutations were used as controls for the $A E 1$ analysis. The SAO (or Ex11 $\Delta 27$ ) mutation was analyzed by amplification in exon 11 region of $A E 1$ by PCR. The sequences of forward and reverse primers used were: 5'-CCTCACCTCCTCCAGCTACTCC-3' and 5'-CAGAAGTT

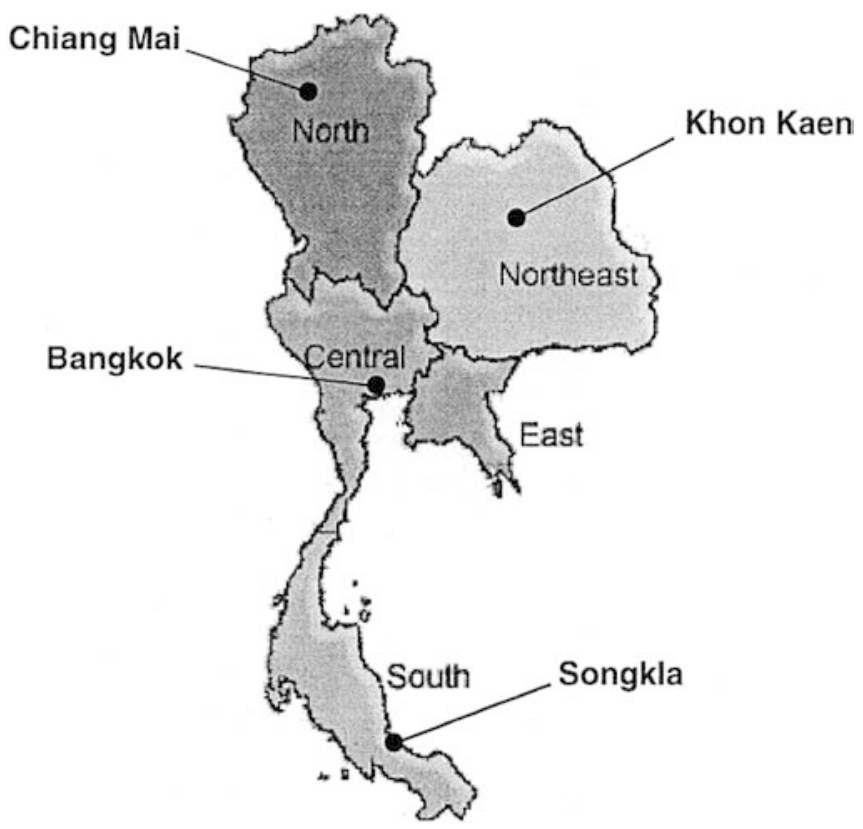

Fig. 1 Map of Thailand showing the four geographic regions, viz., Chiang Mai (North), Khon Kaen (Northeast), Bangkok (Central), and Songkla (South), from which blood samples were collected for $A E 1$ analysis
GGGGCTGAGACAGAG-3', respectively. PCR was performed as previously described (Vasuvattakul et al. 1999). The PCR products were detected by agarose-gel electrophoresis, stained with ethidium bromide, examined on a UV transilluminator, and recorded by photography. The amplified DNA fragment of normal exon 11 was $318 \mathrm{bp}$ in length, whereas that of SAO was $291 \mathrm{bp}$. The sample with the heterozygous SAO mutation showed fragments from the normal exon 11 (318 bp) and the deleted exon 11 (291 bp).

The G701D mutation was analyzed by amplification in exon 17 region of $A E 1$ by PCR and digestion with restriction enzyme HpaII before detection by agarose-gel electrophoresis as described above. The sequences of forward and reverse primers used were: 5'-TGGGCTCAACTATATGAACC-3' and 5'-TTGATACCTTT TTGAAGGGG-3', respectively. The amplified product was 321 bp in length. In the absence of the G701D mutation, the amplified product could be digested with $H$ paII, producing two fragments of $254 \mathrm{bp}$ and $67 \mathrm{bp}$ in length. In the presence of the G701D mutation, the enzyme could not cleave the amplified product, because the restriction site was abolished, and the product remained $321 \mathrm{bp}$ long. The sample with heterozygous the G701D mutation showed three fragments of $321 \mathrm{bp}, 254 \mathrm{bp}$, and $67 \mathrm{bp}$.

Since other genotypes with compound heterozygosities, including $\mathrm{SAO} / \mathrm{R} 602 \mathrm{H}$ (Wilairat 2000), $\mathrm{SAO} / \Delta \mathrm{V} 850, \mathrm{SAO} / \mathrm{A} 858 \mathrm{D}$, $\Delta \mathrm{V} 850 / \Delta \mathrm{V} 850$, and $\Delta \mathrm{V} 850 / \mathrm{A} 858 \mathrm{D}$ (Bruce et al. 2000), were identified in the patients with dRTA from southern Thailand, Malaysia and Papua New Guinea, the R602H, $\Delta$ V850, and A858D mutations were also examined in the southern Thai population in the present study. The methods used were allele-specific amplification (ASA) for R602H, SSCP for $\Delta \mathrm{V} 850$, and PCR followed by $B g / \mathrm{I}$ digestion for A858D.

The allele frequency of each mutation was calculated from the number of individuals carrying the mutation in the subject group from four geographic regions. The occurrences of homozygosity of SAO and G701D were also estimated from their allele frequencies.

\section{Results}

The results of $A E 1$ analyses for the SAO mutation by PCR and electrophoresis and for the G701D mutation by PCR followed by HpaII digestion and electrophoresis are shown in Fig. 2. The analysis of the SAO and G701D mutations in DNA samples from 844 subjects demonstrated that the two mutations were present in the heterozygous condition in seven and five individuals, respectively (Table 1). All seven SAO heterozygotes were found in the southern Thai population; none was observed in the studied populations from other regions of Thailand. Of five G701D heterozygotes, one was found in the northern, three in the northeastern, and one in the central populations. The G701D mutation was not detected in the southern population. The allele frequency of SAO in the southern population was 0.0170 , whereas the allele frequencies of G701D in the northern, northeastern, and central populations were 0.0023 , 0.0073 , and 0.0023 , respectively. Although the SAO mutation was found to be common in the southern Thai population, the G701D mutation had a higher allele frequency in the northeastern Thai population than in the populations of other regions.

From their allele frequencies, the occurrence of SAO homozygote was estimated to be 1 per 3,300 individuals in the southern Thai population and that of G701D homozygotes in northern, northeastern, and central 
Thai populations to be 1 per 200,000, 1 per 20,000, and 1 per 200,000, respectively.

The analyses of $A E 1 \mathrm{R} 602 \mathrm{H}, \Delta \mathrm{V} 850$, and A858D mutations in 206 subjects of the southern Thai population showed the absence of these three mutations in the subjects examined.

\section{A. SAO mutation}

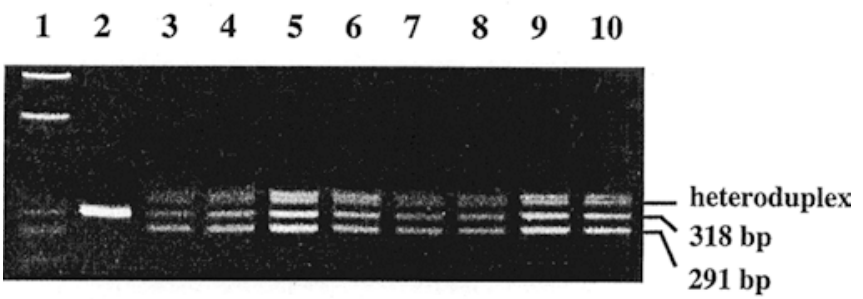

B. G701D mutation

$$
\begin{array}{llllllllll}
1 & 2 & 3 & 4 & 5 & 6 & 7 & 8 & 9 & 10
\end{array}
$$

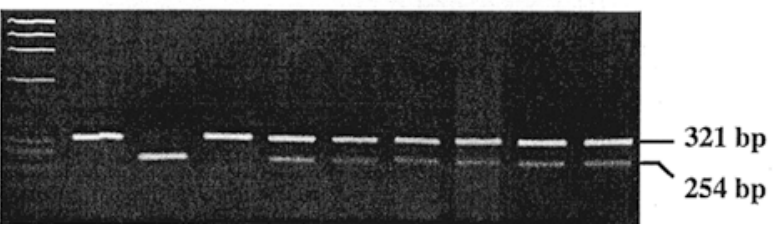

Fig. 2A, B Analyses of $A E 1$ SAO and G701D mutations. A The SAO mutation was analyzed by amplification in the exon 11 region of $A E 1$ by PCR and agarose-gel electrophoresis. Lane 1 Standard DNA markers, PhiX174/HaeIII, lane 2 a normal control sample, showing a fragment of $318 \mathrm{bp}$, lane 3 sample from an individual with a known heterozygous SAO mutation, showing two fragments of $318 \mathrm{bp}$ and $291 \mathrm{bp}$ and two bands of heteroduplex DNA, lanes 4-10 samples from seven subjects with heterozygous SAO mutations, showing the same pattern as that in lane 3. B The G701D mutation was analyzed by amplification in the exon 17 region of $A E 1$ with PCR, followed by restriction enzyme-HpaII digestion and agarose-gel electrophoresis. Lane 1 Standard DNA markers, PhiX174/HaeIII, lane 2 undigested normal control sample, showing a fragment of $321 \mathrm{bp}$, lane $3 \mathrm{HpaII}$-digested normal control sample, showing a fragment of $254 \mathrm{bp}$ but no observable fragment of $67 \mathrm{bp}$, lane $4 \mathrm{HpaII}$-digested sample from an individual with a known homozygous G701D mutation, showing only an undigested fragment of $321 \mathrm{bp}$, lane $5 \mathrm{HpaII}$-digested control sample from an individual with a known heterozygous G701D mutation, showing both undigested and digested fragments of $321 \mathrm{bp}$ and $254 \mathrm{bp}$, respectively, lanes 6-10 HpaII-digested samples from five subjects with heterozygous G701D mutation studied, showing the same pattern as that in lane 5

\section{Discussion}

Although $A E 1$ defects are known to result in erythrocyte disorders, a great deal of attention has recently been paid to the analyses of $A E 1$ mutations in the patients with dRTA, since mutations of this gene have also been found to be involved in the pathogenesis of dRTA. The $A E 1$ abnormality thus shows a pleiotrophic effect, causing seemingly unrelated defects in two different cell types. However, the two disorders may co-exist in some individuals. Baehner and colleagues (1968) first recognized the association between erythrocyte abnormality and dRTA in affected children in a Filipino family, but Wrong and co-workers (1996) were the first to suspect a common molecular basis for SAO and dRTA. The finding that compound heterozygosity between the SAO and G701D mutations caused the combined defects of SAO and dRTA was originally reported by our group (Vasuvattakul et al. 1999). This was confirmed and extended to other types of compound heterozygosity (Bruce et al. 2000). Recent studies in Thailand (Tanphaichitr et al. 1998; Vasuvattakul et al. 1999; Yenchitsomanus et al. 2002) and in other countries of Southeast Asia and Melanesia (Bruce et al. 2000; Wrong et al. 2002) clearly indicate that a group of particular $A E 1$ mutations could cause AR dRTA, these mutations being different from the $A E 1$ mutations found to be associated with AD dRTA (Bruce et al. 1997; Jarolim et al. 1998; Karet et al. 1998; Sritippayawan et al. 2003). The molecular mechanism by which different $A E 1$ mutations give rise to either AR or AD dRTA remains to be elucidated.

Since several cases of AR dRTA caused by compound heterozygous (SAO/G701D) and homozygous (G701D/G70D) mutations of $A E 1$ have been found in Thailand (Tanphaichitr et al. 1998; Vasuvattakul et al. 1997; Yenchitsomanus et al. 2002), it is of great interest to study the prevalence of the mutant SAO and G701D alleles in the Thai population. The results of mutation analyses in the present study show that these two mutations are present in considerable frequencies in the populations from different geographic regions. SAO is common in the southern Thai population but it has not been observed in the populations from three other regions. A previous study has shown that SAO is not present in many ethnic groups in Thailand (Kimura
Table $1 A E 1$ SAO and G701D mutations in populations from four geographic regions of Thailand

\begin{tabular}{|c|c|c|c|c|c|}
\hline \multirow[t]{3}{*}{ Region } & \multirow[t]{3}{*}{ Number of subjects } & \multicolumn{4}{|l|}{$A E 1$ mutation } \\
\hline & & \multicolumn{2}{|l|}{ SAO } & \multicolumn{2}{|l|}{ G701D } \\
\hline & & $\begin{array}{l}\text { Number of } \\
\text { heterozygotes }\end{array}$ & $\begin{array}{l}\text { Allele } \\
\text { frequency }\end{array}$ & $\begin{array}{l}\text { Number of } \\
\text { heterozygotes }\end{array}$ & $\begin{array}{l}\text { Allele } \\
\text { frequency }\end{array}$ \\
\hline North & 216 & 0 & 0 & 1 & 0.0023 \\
\hline Northeast & 205 & 0 & 0 & 3 & 0.0073 \\
\hline Central & 217 & 0 & 0 & 1 & 0.0023 \\
\hline South & 206 & 7 & 0.0170 & 0 & 0 \\
\hline Total & 844 & 7 & 0.0041 & 5 & 0.0030 \\
\hline
\end{tabular}


et al. 1998); it has also not been found in a small number of subjects (43 individuals) in an ethnic group from southern Thailand. In another study on SAO in the southern Thai population, 44 of 1,556 individuals were reported to be SAO heterozygotes (allele frequency: 0.0141; Nopparatana et al. 1996). The allele frequency of SAO in our study (0.0170) is slightly different from that found in the previous work. This may be attributable to variation in sampling. The high frequencies of SAO in Southeast Asian and Melanesian populations may be related to its selective survival advantage against malaria infection; individuals with SAO are less susceptible to cerebral malaria (Allen et al. 1999). SAO homozygosity in southern Thai population would be expected, from its allele frequency, to be about 1 per 3,300 individuals. However, SAO homozygotes have never been observed, suggesting that it is a lethal condition (Liu et al. 1994; Mgone et al. 1996). The abnormality in the SAO homozygote may involve severe abnormalities of both erythrocyte and kidney. The high prevalence of the SAO allele in some regions of Southeast Asia and Melanesia where malaria is endemic, despite its homozygous condition probably being lethal, indicates that a balanced polymorphism might occur in such regions.

In contrast, the G701D mutation has been detected in northern, northeastern, and central Thai populations but is not found in southern Thai subjects. It is not known whether this allele confers an advantage against malaria infection. The allele frequency of the G701D mutation in the northeastern population (0.0073) was higher than that in the northern and central populations (0.0023). The estimated occurrence rates of G701D homozygosity in the northeastern, northern, and central Thai populations are 1 per 20,000, 1 per 200,000, and 1 per 200,000 , respectively. In total, there should be several hundred cases of dRTA attributable to the homozygous G701D mutation. However, the actual incidence rates of this condition seem to be very low. Only a few cases have been observed. One explanation is possibly that this disease is not noticed and that many children with this disease die at an early age.

The higher allele frequency of the G701D mutation in the northeastern population was in agreement with our observation that all Thai patients with AR dRTA resulting from the homozygous G701D mutation were northeastern. Thus, the G701D mutation might anciently originate in this population and might later have spread to other regions. If this is the case, the presence of compound heterozygous $\mathrm{SAO} / \mathrm{G} 701 \mathrm{D}$ in the southern Thai (Vasuvattakul et al. 1999) and Malaysian (Bruce et al. 2000) patients with AR dRTA and its apparent absence in northeastern Thai patients indicate that the G701D allele might have migrated to the southern peninsular region. The SAO allele, on the other hand, has not spread from southern Thailand to central, north, and northeast Thailand because, in the past, the southern Thai people might not migrate to other parts of the country. The southern region is a highly fertile land and rich in natural resources, when compared with other parts of Thailand, especially the northeastern region. This has been an important factor in maintaining the population in the region. The situation might change as later on people migrate for social, economic, and educational reasons. Thus, the SAO allele constitutes a genetic background of the southern Thai population, providing an increased chance for the occurrence of dRTA. The introduction of a new allele, such as G701D, from the migration of the population from the northeastern and other regions to the southern area will result in their pathogenic allelic interaction.

Acknowledgements This work was supported by a grant from the National Center for Biotechnology and Genetic Engineering (BIOTEC grant no. BT-B-07-MG-B4-4501) under the National Science and Technology Development Agency (NSTDA), Bangkok, Thailand. We are grateful to Dr. Prida Malasit, the Director of Division of Medical Molecular Biology, the Director of Medical Biotechnology Unit, and the recipient of Senior Research Scholar Award of Thailand Research Fund (TRF), for his kind and continuous support.

\section{References}

Allen SJ, O'Donnell A, Alexander ND, Mgone CS, Peto TE, Clegg JB, Alpers MP, Wheatherall DJ (1999) Prevention of cerebral malaria in children in Papua New Guinea by Southeast Asian ovalocytosis band 3. Am J Trop Med Hyg 60:1056-1060

Alper SL (2002) Genetic diseases of acid-base transporters. Annu Rev Physiol 64:899-923

Baehner RL, Cilchrist GS, Anderson EJ (1968) Hereditary elliptocytosis and primary renal tubular acidosis in a single family. Am J Dis Child 115:414-419

Batlle D, Ghanekar H, Jain S, Mitra A (2001) Hereditary distal renal tubular acidosis: new understandings. Annu Rev Med $52: 471-484$

Bruce LJ, Tanner MJ (1996) Structure-function relationships of band 3 variants. Cell Mol Biol 42:975-984

Bruce LJ, Cope DL, Jones GK, Schofield AE, Burley M, Povey S, Unwin RJ, Wrong O, Tanner MJA (1997) Familial distal renal tubular acidosis is associated with mutations in the red cell anion exchanger (band 3, AEl) gene. J Clin Invest 100:16931701

Bruce LJ, Wrong O, Toye AM, Young MT, Ogle G, Ismail Z, Sinha AK, McMaster P, Hwaihwanje I, Nash GB, Hart S, Lavu E, Palmer R, Othman A, Unwin RJ, Tanner MJ (2000) Band 3 mutations, renal tubular acidosis and South-East Asian ovalocytosis in Malaysia and Papua New Guinea: loss of up to $95 \%$ band 3 transport in red cells. Biochem J 350:41-51

Jarolim P, Palek J, Amato D, Hassan K, Sapak P, Nurse GT, Rubin HL, Zhai S, Sahr KE, Liu S-C (1991) Deletion in erythrocyte band 3 gene in malaria-resistant Southeast Asian ovalocytosis. Proc Natl Acad Sci USA 88:11022-11026

Jarolim P, Shayakul C, Prabakaran D, Jiang L, Stuart-Tilley A, Rubin HL, Simova S, Zavadil J, Herrin JT, Brouillette J, Somers MJG, Seemanova E, Brugnara C, Guay-Woodford LM, Alper SL (1998) Autosomal dominant distal renal tubular acidosis is associated in three families with heterozygosity for the $\mathrm{R} 589 \mathrm{H}$ mutation in the $\mathrm{AE} 1$ (band 3) $\mathrm{Cl}^{-} / \mathrm{HCO}_{3}{ }^{-}$exchanger. J Biol Chem 273:6380-6388

Karet FE, Gainza FJ, Gyory AZ, Unwin Rj, Wrong O, Tanner MJ, Nayir A, Alpay H, Santos F, Hulton SA, Bakkaloglu A, Ozen S, Cunningham MJ, Di Pietro A, Walker WG, Lifton RP (1998) Mutations in the chloride-bicarbonate exchanger gene AE1 cause autosomal dominant but not autosomal recessive distal renal acidosis. Proc Natl Acad Sci USA 95:6337-6342 
Kimura M, Shimizu Y, Ishida WS, Soemantri A, Tiwawech D, Romphruk A, Duangchan P, Ishida T (1998) Twenty-seven base pair deletion in erythrocyte band 3 protein gene responsible for Southeast Asian ovalocytosis is not common among southeast Asians. Hum Biol 70:993-1000

Kollert-Jons A, Wagner S, Hubner S, Appelhans H, Drenckhahn D (1993) Anion exchanger 1 in human kidney and oncocytoma differs from erythroid AE1 in its $\mathrm{NH}_{2}$ terminus. Am J Physiol 265:F813-F821

Liu S-C, Jarolim P, Rubin HL, Palek J, Amato D, Hassan K, Zaik M, Sapak P (1994) The homozygous state for the band 3 protein mutation in Southeast Asian ovalocytosis may be lethal. Blood 84:3590-3591

Lux SE, John KM, Kopito RR, Lodish HF (1989) Cloning and characterization of band 3, the human erythrocyte anion-exchange protein (AE1). Proc Natl Acad Sci USA 86:9089-9093

Mgone CS, Koki G, Paniu MM, Kono J, Bhatia KK, Genton B, Alexander NDE, Alpers MP (1996) Occurrence of the erythrocyte band 3 (AE1) gene deletion in relation to malaria endemicity in Papua New Guinea. Trans R Soc Trop Med Hyg 90:228-231

Nopparatana C, Nopparatana C, Kanjanaopas S, Saechan V, Matsuo M (1996) Southeast Asian ovalocytosis (SAO) in the South of Thailand (abstract). PSU-ICMR Symposium, 25-26 July 1996, Songkhla, Thailand

Quilty JA, Li J, Reithmeier RA (2002a) Impaired trafficking of distal renal tubular acidosis mutants of the human kidney anion exchanger kAE1. Am J Physiol Renal Physiol 282:F810-F820

Quilty JA, Cordat E, Reithmeier RA (2002b) Impaired trafficking of human kidney anion exchanger (kAE1) caused by heterooligomer formation with a truncated mutant associated with distal renal tubular acidosis. Biochem J 368:895-903

Rodriguez-Soriano J (2000) New insights into the pathogenesis of renal tubular acidosis - from functional to molecular studies. Pediatr Nephrol 14:1121-1136

Sahr KE, Taylor WM, Daniels BP, Rubin HL, Jarolim P (1994) The structure and organization of the human erythroid anion exchanger (AE1) gene. Genomics 24:491-501
Sritippayawan S, Kirdpon S, Vasuvattakul S, Wasanawatana S, Susaengrat W, Waiyawuth W, Nimmannit S, Malasit P, Yenchitsomanus P (2003) A de novo R589C mutation of anion exchanger 1 causing distal renal tubular acidosis. Pediatr Nephrol 18:644-648

Tanner MJ (1993) Molecular and cellular biology of the erythrocyte anion exchanger (AE1). Semin Hematol 30:34-57

Tanner MJ (1997) The structure and function of band 3 (AE1): recent developments. Mol Membr Biol 14:155-165

Tanphaichitr VS, Sumboonnaonda A, Ideguchi JH, Shayakul C, Brugnara C, Takao M, Veerakul G, Alper SL (1998) Novel AE1 mutations in recessive distal renal tubular acidosis: loss-offunction is rescued by glycophorin A. J Clin Invest 102:21732179

Tse WT, Lux SE (1999) Red blood cell membrane disorders. Br J Haematol 104:2-13

Vasuvattakul S, Yenchitsomanus P, Vachuanichsanong P, Thuwajit P, Kaitwatcharachai C, Laosombat V, Malasit P, Wilairat P, Nimmannit S (1999) Autosomal recessive distal renal tubular acidosis associated with Southeast Asian ovalocytosis. Kidney Int 56:1674-1682

Wilairat P (2000) Renal tubular acidosis, anion exchanger 1 (AE1) mutations. Southeast Asian ovalocytosis: a malaria connection? FAOPS Newsletter 9:3-8

Wrong O, Unwin RJ, Cohen E, Tanner M, Thakker R (1996) Unravelling of the molecular mechanism of kidney stones. Lancet 348:1561-1565

Wrong O, Bruce L, Unwin RJ, Toye AM, Tanner MJA (2002) Band 3 mutations, distal renal tubular acidosis, and Southeast Asian ovalocytosis. Kidney Int 62:10-19

Yenchitsomanus P, Vasuvattakul S, Kirdpon S, Wasanawatana S, Susaengrat W, Sreethiphayawan S, Chuawatana D, Mingkum $\mathrm{S}$, Sawasdee N, Thuwajit $\mathrm{P}$, Wilairat $\mathrm{P}$, Malasit P, Nimmannit $\mathrm{S}$ (2002) Autosomal recessive distal renal tubular acidosis caused by G701D mutation of anion exchanger 1 gene. Am J Kidney Dis 40:21-29 